
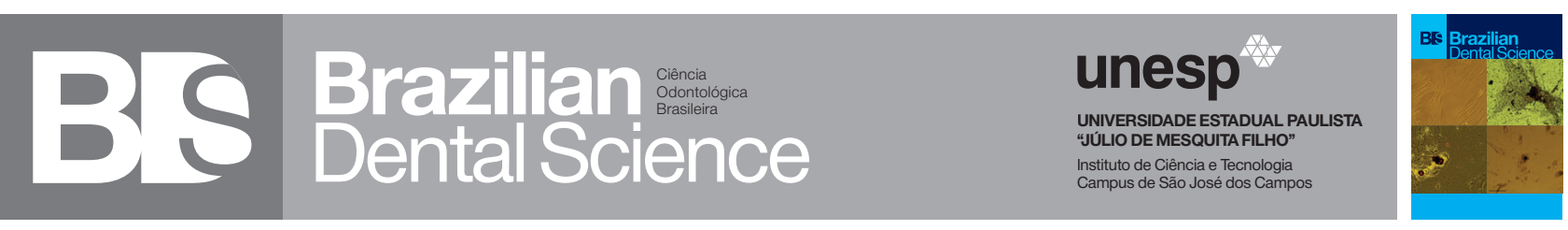

\title{
(i)
}

\section{Gardner Syndrome imaging features in plain radiographs and computed tomography: a case report}

Síndrome de Gardner: Características imaginológicas por meio da radiografia convencional e tomografia computedorizada.

Luciana MUNHOZ ${ }^{1}$, Christyan Hiroshi IIDA ${ }^{1}$, Emiko Saito ARITA ${ }^{1}$, Plauto Christopher Aranha WATANABE ${ }^{2}$

1 - Department of Stomatology - School of Dentistry - São Paulo University - São Paulo - SP - Brazil.

2 - Department of Stomatology - Public Oral Health and Forensic Dentistry - Ribeirão Preto Dental School - University of São Paulo Ribeirão Preto - SP - Brazil.

\section{ABSTRACT}

Gardner syndrome (GS) is a genetic disease with high penetration characterized by a signal triad of colonic polyposis, multiple osteomas and mesenchymal tumors in the soft tissues and skin. The colonic polyposis is associated to the development of malignant disease. Patients may also present maxillomandibular alterations such as impacted teeth, supernumerary teeth, congenital missing teeth and odontomas. Bone lesions and maxillomandibular alterations usually precedes the gastrointestinal alterations; hence dentists should be aware of GS syndrome main radiographic signals, in order to detect the disease and proper referred the patient to medical treatment and surveillance. Thus, in this report, it is described a case of GS in a male patient, as well as discussed GS features.

\section{KEYWORDS}

Gardner syndrome; Oral diagnosis; Panoramic radiograph; Computed tomography; Osteoma; Bone neoplasms.

\section{RESUMO}

A síndrome de Gardner (GS) é uma doença genética caracterizada pela seguinte tríade: polipose colônica, múltiplos osteomas e tumores mesenquimais em tecidos moles e pele. A polipose colônica está associada ao desenvolvimento de tumores malignos. Os pacientes também podem apresentar alterações maxilomandibulares, como dentes impactados, dentes supranumerários, agenesia congênita e odontomas. Lesões ósseas e alterações maxilomandibulares geralmente precedem as alterações gastrointestinais; portanto, os dentistas devem estar cientes dos principais sinais imaginológicos da GS, a fim de detectar a doença e encaminhar adequadamente o paciente para tratamento. Neste relato de caso é descrito um caso de GS em um paciente do gênero masculino, além de discutir as características da GS.

\section{PALAVRAS-CHAVE}

Síndrome de Gardner; Diagnóstico bucal; Radiografia panorâmica; Tomografia computadorizada; Osteoma; Neoplasias ósseas.

\section{INTRODUCTION}

T n 1951, Eldon J Gardner [1] published a $\perp$ clinical study of intestinal polyposis as a predisposing factor for carcinomas in the lower digestive tract. The researcher also noticed that patients with the aforementioned polyposis had several superficial prominent masses in the head and observed that the disease affected individuals from the same family, suggesting a genetic dominant hereditary pattern. The genetic disease described by Gardner was further named as "Gardner Syndrome" (GS). GS has a high degree of penetration and is characterized by a signal triad of colonic polyposis, multiple osteomas and mesenchymal tumors in the soft tissues and skin [2].

Nowadays, the GS genetic involvement is partially understood. The syndrome is a result 
of the mutation of the anaphase-promoting complex gene (APC), which is located on the long arm of chromosome $5 * 5 q 21-22$ ). Although the mutation in APC which leads to intestinal disease was already identified, other modifier genes responsible for the development of the extraintestinal manifestations of GS remains unknown [3]. In approximately $75 \%$ of the cases, the defective gene is inherited from one of the parents [3].

The presence of osteomas in the craniofacial area precedes the development of the intestinal lesions [4], hence, the proper diagnosis, eventually oriented by the dental professional, may be beneficial to the patient which can be properly referred to early medical treatment. Osteomas are a benign slow proliferation of compact or medullary bone neoplasms that can present as central, peripheral or extra-skeletal [4]. . Osteomas are frequently asymptomatic, but can produce tumefaction [4]. and they are usually located in the jaws and frontal bone. [3]. Besides osteomas, GS patients may present dental anomalies, such as impacted and/or supernumerary teeth, odontomas and congenitally missing teeth [3]. . In this report, it is presented a case of a male patient with GS with multiple osteomas and discussed the main imaging features observed in plain radiographs and tomographic examinations.

\section{CASE REPORT}

\section{Case history and clinical findings}

A male patient, 64 years old, was referred to oncologic, gastroenterological and dentistry treatment at the Hospital das Clínicas de Ribeirão Preto, São Paulo University, Brazil. Patient mentioned previous cancer treatment (grade 2 colorectal adenocarcinoma) at age 58. Patient denied history of cancer in his family and mentioned previous diagnosis of GS. As he needed dental treatment and have an esthetic complaint about a protuberance in his mandible, further imaging examinations were requested.

\section{Imaging findings}

The first examination performed was a panoramic radiograph which evinced multiple radiopaque areas in mandible body and angle, mandible head and maxilla, as demonstrated in Figure 1. The radiopaque areas had heterogeneous radiodensity and were roundshaped.

A lateral oblique image was requested, and the radiopaque areas rounded-shaped in mandible were noticed as exophytic masses, mainly in the mandible angle (Figure 2). Furthermore, the anterior mandible and mandible head radiopaque areas could be confirmed in this radiographic examination.

Then, the patient was referred to computed tomography (CT) examinations. Mandible CT revealed that the radiopaque lesion in mandible body was, in fact, exophytic, with an elongated shape, both on axial and sagittal slices, as demonstrated in Figure 3.

In Figure 4, a tridimensional CT imaging of the elongated exophytic hyperdense lesion in the mandible body, nearby the mental foramen is exhibited.

Mandible head was also verified in CT examinations. The hyperdense lesions were present in the right side, as observed in panoramic radiographs. In Figure 5 it is shown the hyperdense lesions in mandible head, first in tomographic slices (Figure 5A) and then in an illustrative tridimensional reconstruction (Figure 5B). In CT sagittal slices (Figure 5A) evincing mandible head, it can be observed that the exophytic lesion has multiple radiopaque round-shaped nodules leading to a deformity in mandible head.

\section{DISCUSSION}

GS is characterized by multiple lesions that affect the skeleton, skin, colon and retina. [5]. Although these lesions should be treated, the most severe involvement is the malignant transformation of the intestinal polyps, which may result in patient death or the need of oncologic interventional treatment. Eventually, when the family history is unknown, the 
diagnosis of GS may be incidental, as osteomas and dental abnormalities precedes the intestinal polyps and can be asymptomatic [6]

Osteomatosus lesions, such as the sclerotic lesions presented in the case report, are observed in $46 \%$ to $93 \%$ of the GS patients [7]. These lesions can be verified in panoramic radiographs with 2 patterns: focal or widespread.[8]. Furthermore, lesions have slow growth, often reaching a stationary size [6]. GS osteomas can occur in maxilla and/or mandible; however enostoses and exostoses are usually observed in mandible [7]. The main location of enostoses are in premolar/molar alveolar bone region, whereas exostoses are often noticed in mandibular angle, tuberculum articulare and zygomatic arch [7]. In the present report, one of the exostoses was verified in the mandible head and, similarly to the previously exposed in literature, also in mandible angle. The sclerosis widespread pattern was also seen in maxilla and mandible body.

The differential radiographic diagnosis of GS includes other pathologies with multiple bone sclerosis areas, odontomas or impacted/ supernumerary teeth such cleidocranial dysplasia, osteo-cemental dysplasia and periapical osteo-cemental dysplasia [4]. However, cleidocranial dysplasia can be easily differentiated from GS when clinical patient features are available, as the skeletal deformities inherent to syndrome.

The main imaging tools used for GS diagnostic are plain radiographs, such as panoramic radiograph and cranial techniques, and CT can be performed to detail the lesions, allowing to identify the location, size and adjacent compromise structures.

Although bone lesions can be detected before the intestinal manifestations occur, the final diagnosis of GS is based on genetic testing. Early diagnosis of the disease may prevent malignant transformation, mainly colorectal adenocarcinoma, of the intestinal polyps [8]. GS patients also presents increased risk of cancer in other organs, hence, oncologic surveillance of these patients is highly recommended [6]. . The control protocol GS patients includes large bowel, upper gastrointestinal, thyroid and hepatic periodic examinations [9].

The treatment of GS bone lesions involves surgery, when function or esthetics are compromised. For colorectal polyps, the treatment includes healthy diet, the use of nonsteroid ant inflammatory such as slindac or a Cox2 inhibitors like celecoxib, which can slow the growth of the polyps in the colon, and also surveillance by endoscopies and colonoscopies. If more than 20 polyps are observed, colon removal is recommended in order to reduce the risk of development of colon cancer [10].

In conclusion, the role of the dentistry professional in the detection of bone lesions and maxillomandibular alterations is crucial to the early detection of GS, as these alterations precedes the colorectal disease. Dentists should be aware of this syndrome in order to proper refer the patient to medical treatment or surveillance.

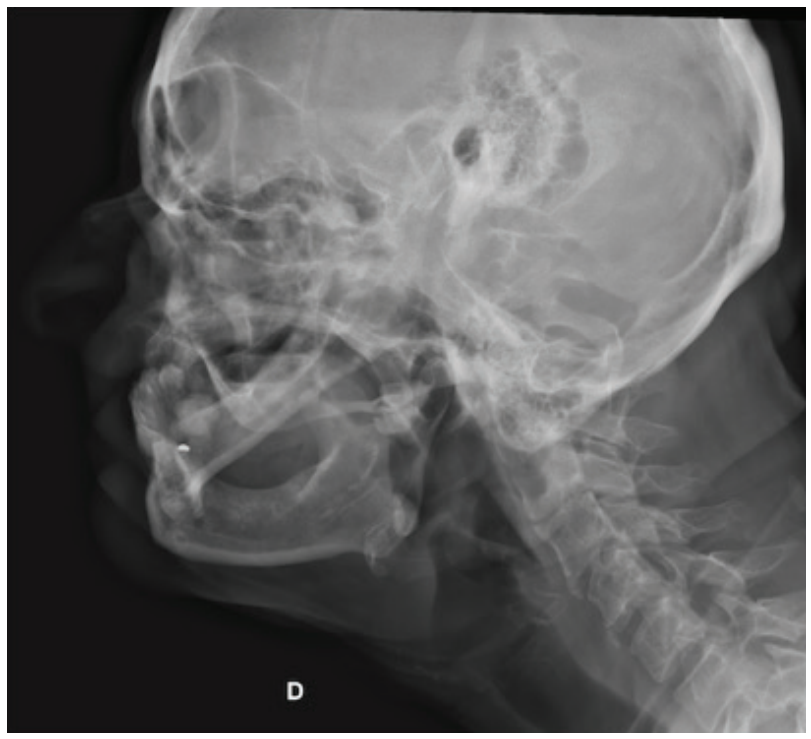

Figure 1 - panoramic radiograph of the case. Multiple radiopaque areas are observed in mandible body and angle, mandible head and maxilla. 


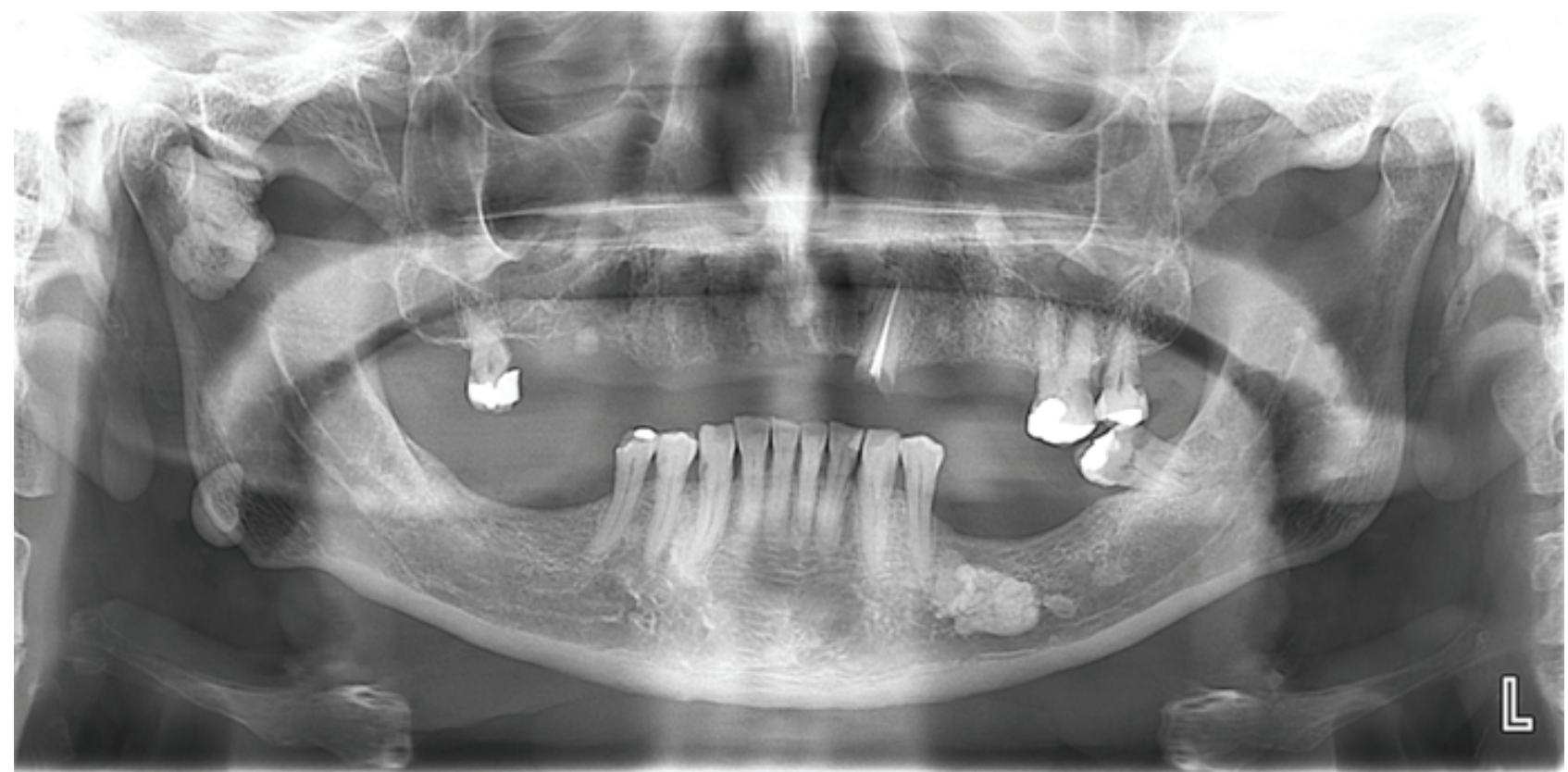

Figure 2 - Oblique radiograph of the case. Note the exophytic feature of the mandible radiopaque mass. Also, a radiopaque lesion was noticed in the posterior area of the cranium.
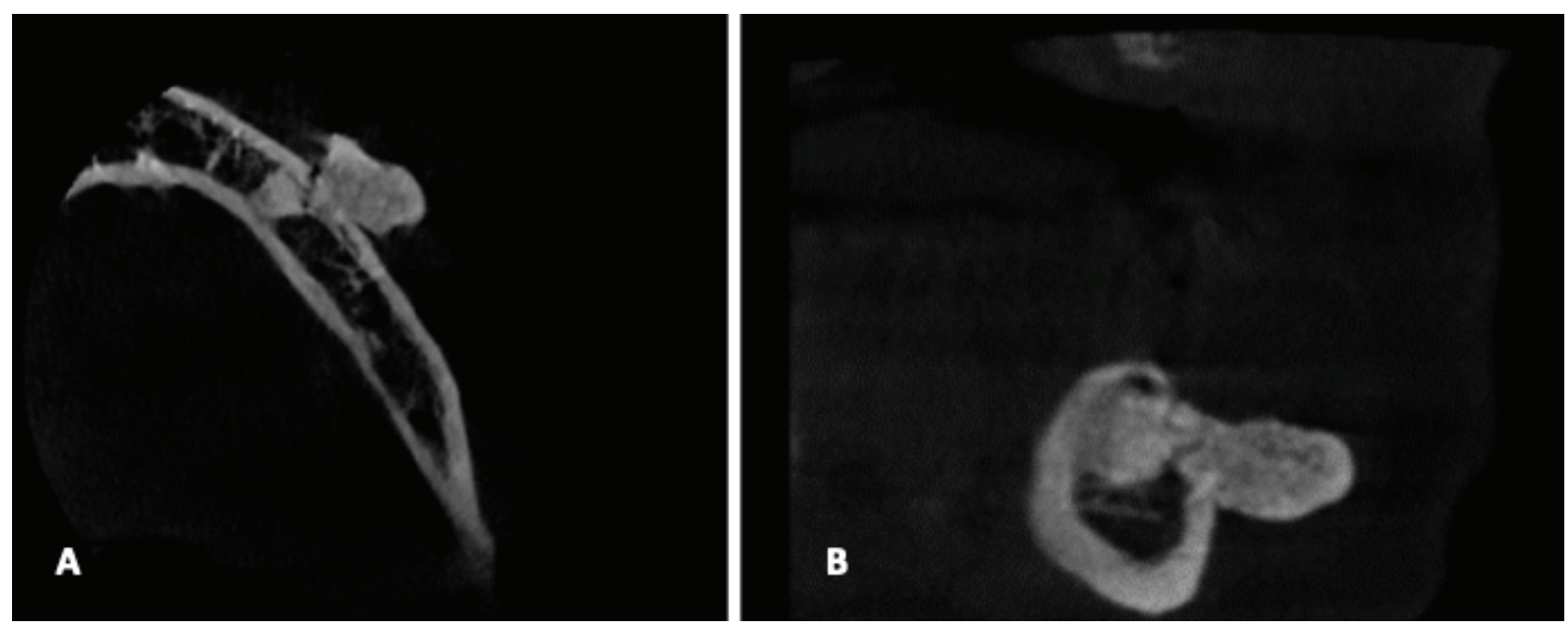

Figure 3 - Computed tomography axial slices of the mandible body showing the exophytic nature of the lesion, with an elongated aspect ( $A$ and $B)$, left size. 

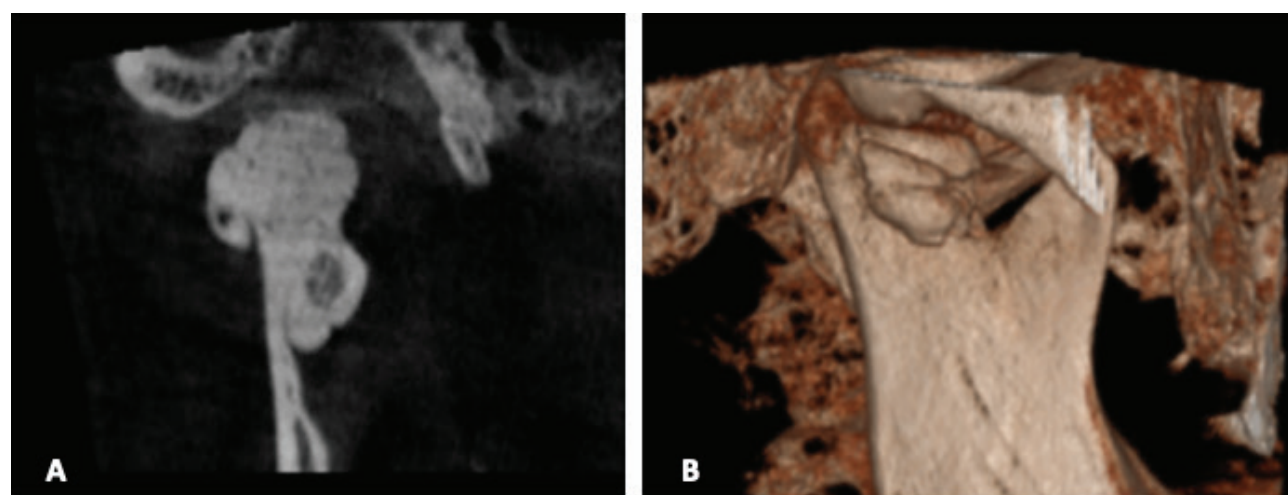

Figure 4 - Tridimensional aspect of the hyperdense lesion.
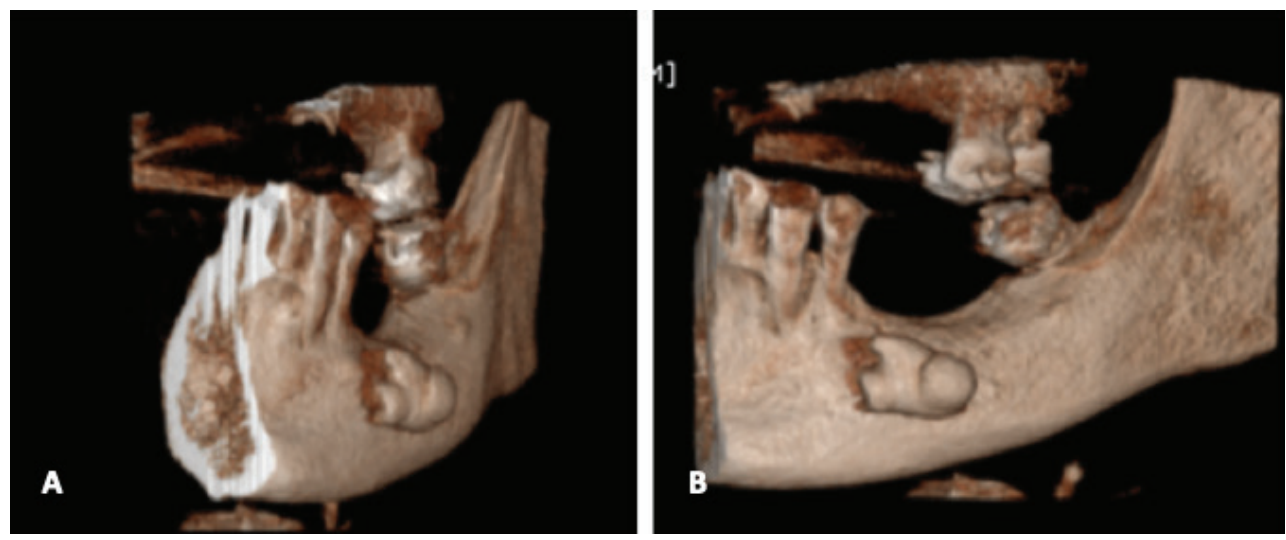

Figure 5 - Computed tomography of the case. Sagital slices showing the hyperdense lesion in mandible head (A) and its tridimensional reconstruction (4B).

\section{REFERENCES}

1. Gardner EJ. A genetic and clinical study of intestinal polyposis, a predisposing factor for carcinoma of the colon and rectum. Am J Hum Genet. 1951 Jun;3(2):167-76.

2. Nandakumar G, Morgan JA, Silverberg D, Steinhagen RM. Familial polyposis coli: clinical manifestations, evaluation, management and treatment. Mt Sinai J Med. 2004 Nov;71(6):384-91.

3. YuD, Ng Cw B, Zhu H, Liu J, Lin Y.Bone and dental abnormalities as first signs of familial Gardner's syndrome in a Chinese family: a literature review and a case report. Med Sci (Paris). 20180ct;34(F1):20-5.

4. Chimenos-Küstner E, Pascual M, Blanco I,Finestres F. Hereditary familial polyposis and Gardner's syndrome: contribution of the odonto-stomatology examination in its diagnosis and a case description. Med Oral Patol Oral Cir Bucal. 2005 Nov-Dec;10(5):402-9.
5. Gardner EJ, Richards RC. Multiple cutaneous and subcutaneous lesions occurring simultaneously with hereditary polyposis and osteomatosis. Am J Hum Genet. 1953 Jun;5(2):139-47.

6. Boffano P,Bosco GF, Gerbino G. The surgical management of oral and maxillofacial manifestations of Gardner syndrome. J Oral Maxillofac Surg. 2010 0ct:68(10):2549-54.

7. Win MA, Keller JJ, Giardiello FM, Brand HS. Oral and maxillofacial manifestations of familial adenomatous polyposis. Oral Dis. 2007 Jul;13(4):3605.

8. Lew D, DeWitt A, Hicks RJ, Cavalcanti MG. Osteomas of the condyle associated with Gardner's syndrome causing limited mandibular movement. J Oral Maxillofac Surg. 1999 Aug;57(8):1004-9.

9. Fotiadis C, Tsekouras DK, Antonakis P,Sfiniadakis J, Genetzakis M, Zografos GC. Gardner's syndrome: a case report and review of the literature. World J Gastroenterol. 2005 Sep;11(34):5408-11.

10. Charifa A Zhang X. Gardner syndrome. StatPearls. 2018 0ct;2019-2018.

\section{Luciana Munhoz}

(Corresponding address)

Department of Stomatology, School of Dentistry, University of São Paulo, Av. Lineu

Prestes, 2227. Zip code: 05508-000. São Paulo, SP, Brazil

Date submitted: 2019 Jun 25

E-mail: dra.lucimunhoz@usp.br 